TIFL SOIAR OPACITIES CONSTRAINFD HY SOIAR NFITTINOS ANI SOI.AR OSE:I I.IATIONS

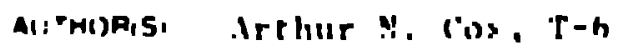

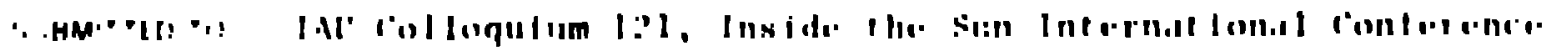

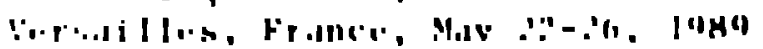

IMS I INIF

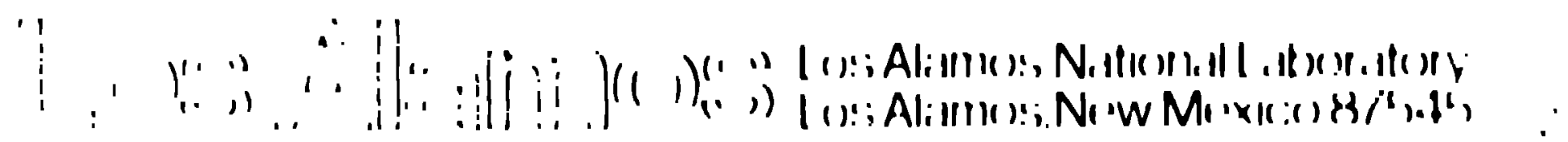




\title{
SOLAR OPACITIES CONSTRAINED BY SOLAR NEUTRINOS AND SOLAR OSCILLATIONS
}

\author{
Arthur N. Ciox \\ Theoretical Division \\ Los Alamoo National laboratory
}

\begin{abstract}
This revirw discusges the currene situation for opacities at the solar center, the solar surface, and for the few million kelvin temperatures that occur below the convection zone. The solar center conditions are impurtant because they are crucial for the neutrino produrtion, which continues to be predicted about 4 times that observed. The main extinction effects there are free-free photon absorption in the electric fields of the hydrogen, helium and the (:NO atoms, free electron scallering of photons, and the bound-free and bound-bound absorption of photons by uron atoms with two electrons in the is bound level. An asumption that the iron is condensed-out helow the convection sone, and the opacity in the central regions is thereby reduced, results in about a 25 percent reduction in the central opacity but only a 5 percent reduction at the base if the convection sore. Furthermore, the f-mode colar oncillations are changed with this asumption, and do not bic the observed unes w weil a for standard models. A discusion of the large effective "pacity reduction by weakly interacting masoive particles (WIMPs or Coamions) abo resulta in poo: anreement with observed p-mode incillation frequencies. The much larger opacities for the solar surfice layers from the Low Alamon Astrnphysical Opacity Library intead of the videly used ('ox and Tubor values show small improventients in ooculation frequency predictiona, but the lagest -Hfer: w in the dwcuation of p-mode stability. Solar acillation frequencies can serve a an opacity -xperiment for ine cemperatures and denetties, reopectively, of a few mullion kelvin and between 0 I (i.1 11 ) ' $m$ ' ('irrent incillation frequency calculatione indicase that possibly the Opacity Labrary vilues nerd ilt inirease of typically 15 perrent juat at the bottom of the convertion sone at $3 \times 10 " \mathrm{~K}$ lipacitien have uncertunties at the phutiophere and deeper than tha convection sone rangung frim ii) in : 5 percent. The equation of state that nupplies data for the opacity calcilationa fortunately his prensure uncertainties of inly shout I percent, but upecity uncertainties will alwayo be muh

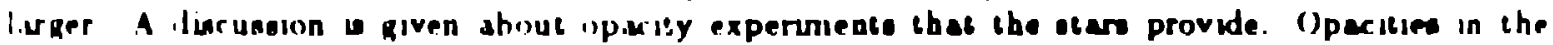

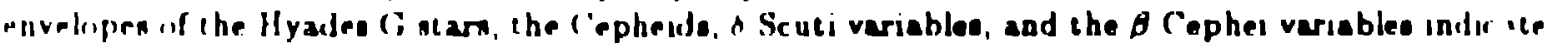

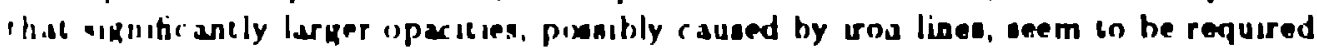

\section{INTRODIIC:TION}

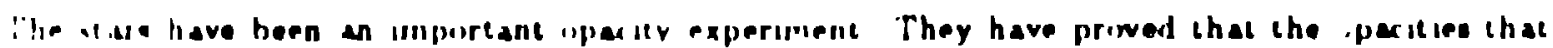

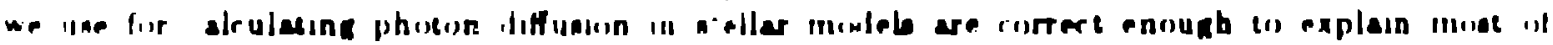

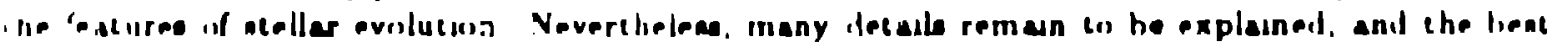

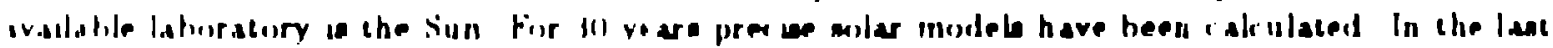

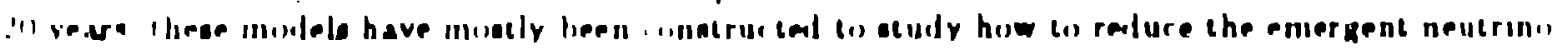

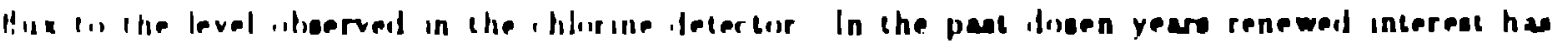

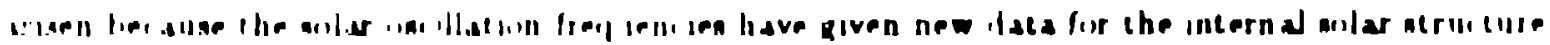

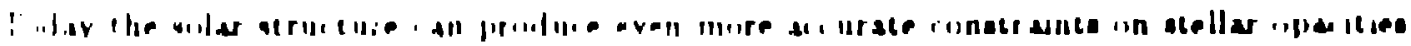


This review !lu cusaps several interesting und current coptes in solar "pacity and gtructure that

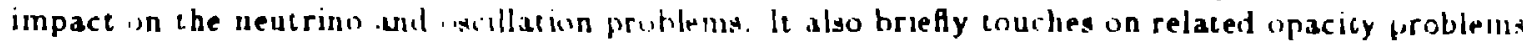
for several ocher classes if atars Fir a review of how stellar opacities are calculated readers shunhl

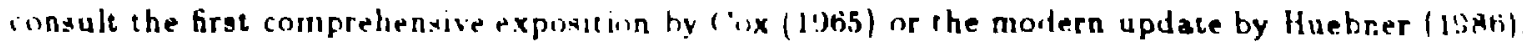
Recent comprehensive tables that we of value in calculating stellas structure have hepn puhlished hy Cox and Tabor (197ib). The Las Alamus Aatrophygical Opacity Library by Huehner ot il] $(1977)$ allows Library wiers in calculate their own mixtured of hydrogen, helium, and the milly wher elementa. Many rables have bern rialoulated ihat way and passed arciund in ither siellar istrophysiciats all aver the wirlul linpefully, the Library we asy enough to uae acrurately. su (hit these tables are all consistent with earh we her.

since the availability of the library, there have be:n a few important specialized pispery I w iussing improvements. Magee, Merts, and Huebner (1984) a well as Igleasas, Kugern, and Wilwoll, $\left(1:, a_{1}\right)$ have searched for opacity inc reases for the giant stars. It is hoped that the extenaive equatun of state (MHD) and opacity investigaturs by Mihalas, Hummer, Dappen, Seacon, and many others will produce a definitive set of ishlea fur the future.

We discuse in this review the current issues for opacities at the solar center. che solas surfare. and in the layera just below the convection zone. We also mention three uther experiments that may help conotrain opacities. These are the lithium problem of the Hyade $G$ stars, the pulation periods of the Cepheids and the s Scuti variables, and the inatability of the $\theta$ Cepher variiblen.

Many researchers calculating stellar atructure use the Los Alamoe nparity iables directly using sperial interpolation procelures. Thu is what we do aloo un cur pubation atudies at Los Alamion when the part of the star if ultereat is inly the homogeneous componition acellar envelope However. we have never incerpolated tetween tables for olellar modele in advanced evolution atages, where the composition w changing throughout the model, we use the equation of atste and opacity fita if scellingwerf (1975ab) and then (1!w5 for the EOS and 1975 for the opacities). We find that tha is sdequate for most all atudies, but may he now nolar atrurture ocudies have berome on sophutic aleil lliat we need to interpolate between tables oumelves.

1) piasties depend cructaliy if the det.sila of the equation of atace. Thus the Los Alamos equation if atate reaules need to he juat as comprehensive as those developed for the MHD equation of atate

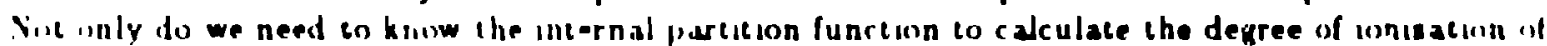
sh element to know the mixture presaur. ond enerky, but we aloo need that same dala co enable us

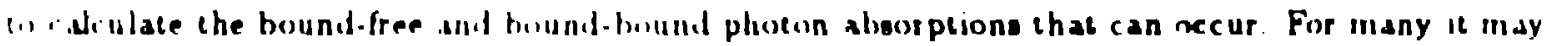

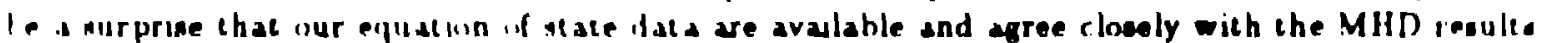
liat huw rineely is a topir niw recerving interest for both equation of atate and opacily otudief

There ha heen conailerahle wrivity lacely on the question a to whecher obellar opacitien nepil i., he increased bersuee many weak lines. especislly frnm uron, have been noglected. Thie wn even though irnn u not a very abundant element in the soler coniposition. Evidence a growing for

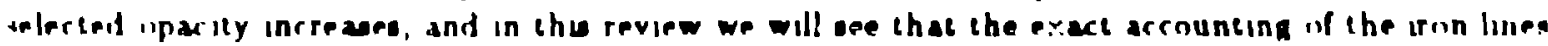
is impirtall fir the enture tiun. from the photouphere cu che rencer

\section{THE MULAR ('ENTER}

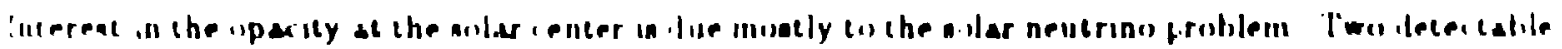

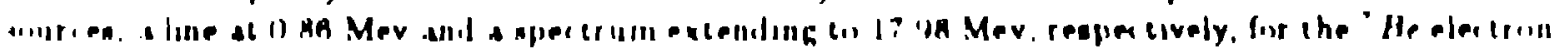

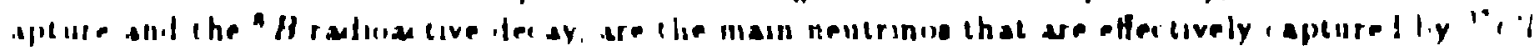

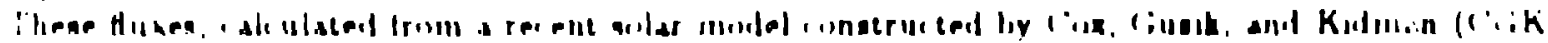

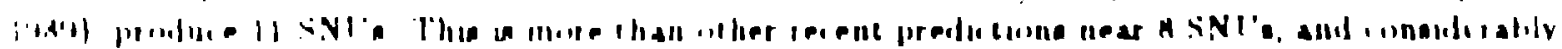

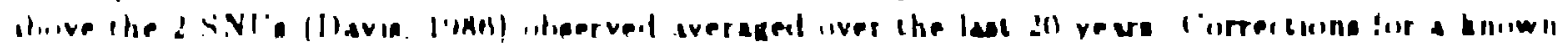

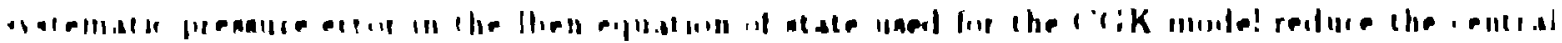


helium concent, the central temperatute. und the neutrino output io about the Bahcal and 1 'Inih

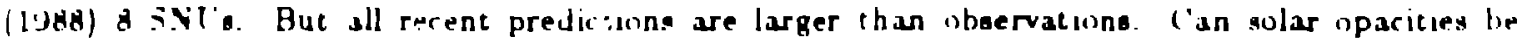
blemed fir this persistent prediction of too many neutrinus?

The wawer for the list 20 years 1 . a heen no. The opacily at the center of the Sun ta upproxim.tely 13 free electron scatering. 13 free free shorption of photone in tise electric field

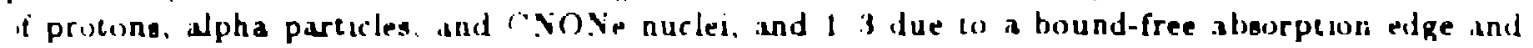
s boind-hound line of highly wnized ionn. These aboorption effecta are simple enough, and the islculation of thes actonustion reliable enough, that the opacity at the center ut the Sun is protibly known to an accuracy of 10 percent. Differences from model to model may be due more i." ompusition changes rather than upacity iacertainties.

Figure I shows the nonochromitic abourption cofficient versus photon energy at $15 \times 10^{\prime \prime} \mathrm{K} . \mathrm{m} \cdot \mathrm{l}$ a tennty of $150, \mathrm{im}^{\mathrm{J}}$, cunditung that ase close to the solar center as calculated for current staniluri\} - Mler inndels. These data come from the EXOP upalily program, the inmediace forerunher if the 1100) program that calculated the monochecmitic aboorption and scattering data for the (1) party L.jbran lt has been used for thu review hecause of to convenience in operation and in pruducing plits. The bound-free photnelectric absorption ecige w caused by liberating the is electron fiom the uron atom with 2 to electrons, 11.628 electrone and $1.72 p$ elec:rons. Thin edge wat the inean pinition of individual edges for the several tonisation staged present. The line is the sum of the is 10 Ip trasustions un the uron tons that are 20, 21, 22, and 23 times ioniaed. The $1 v^{\prime}$ variation at photon enesgies below the abacrption edge is the free-free absorption from all the inna in the muxture includug those from uron. Ahove the edge the contribution of the free electron scatcering becomies inticeable. The fiomeland mean weightung function peake at $h \nu \cdot k T=7.0$, which is just over 9 kev significant weight $w$ in the hand of 35 to ! b kev, oo one can roughly confirm that the mean upacily here w $1.18 \mathrm{im}^{2} \mathrm{y}$

The iron line tranation is to $3 p$ a not seen becauce the $3 p$ level is deatroyed by the large denaity if charges surrounding the uron wne shielding of the nucleus by ibe other bound electrone and the . untinuum depreasion puts the aboorption edge at 73 kev unatead of at 9.2 kev for the configurdtinn with only une bouno electron The resonant wascerung line at 3 kev and weak abeorption lines near

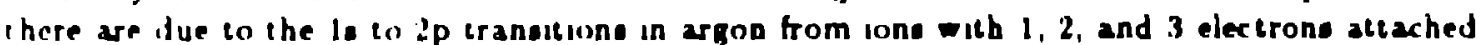

Fipure 2 quves the EX()P monochromatic abeorpeion roeficiento for a cace at the ome temperwiure and denalty where the iron wabeent Thu ise has !een conudered by Dearborn. Marx, ulld

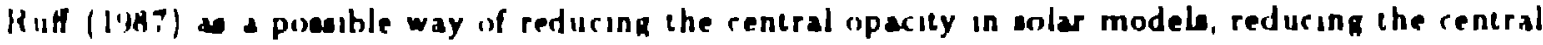
cemperature, and alleviaung the solar neutrino problem. The mean opacity for this case is $0 ! 92$ $\cdot m^{2}$ y The ron line and erge are muang. and that reasits un the 25 percent opacity decrease

'The opacily for the rase where all the $Z$ elements are removed from tbe muxture $10.80 \mathrm{~cm}^{d}$, The cuntribution of completely ionued hyilrogen and helium in producing free-free aboorpion and free elertron actlerine now produces the buil of the opecity

At lan Alamoe we have heen uoung the oular p-modes a an indicator of the internal enlar oparily That is, in sldition to adjustung the mixing length in the atanderd mixing lengeh converticin tipeiry

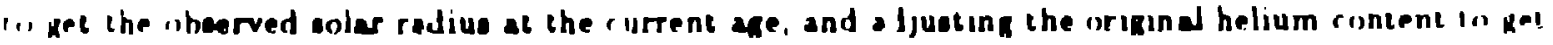

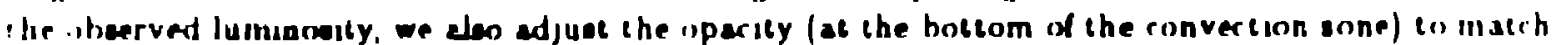

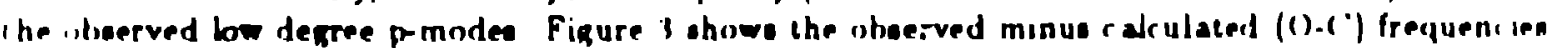

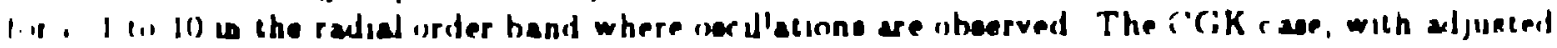

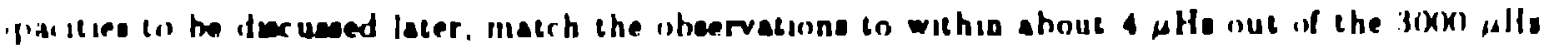

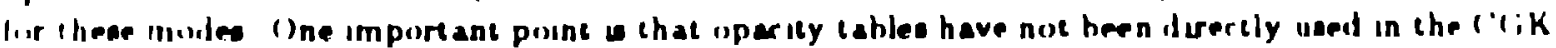

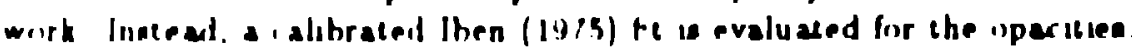

The 13.1 values for the noriron helow the ronvertoon ounea cees are ohown in tigure 4 While the lifferenien are actually millaller, there in a npreal from one I value to the neat This kiven a hint

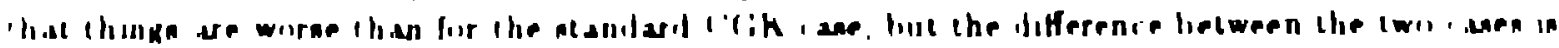
risalie 


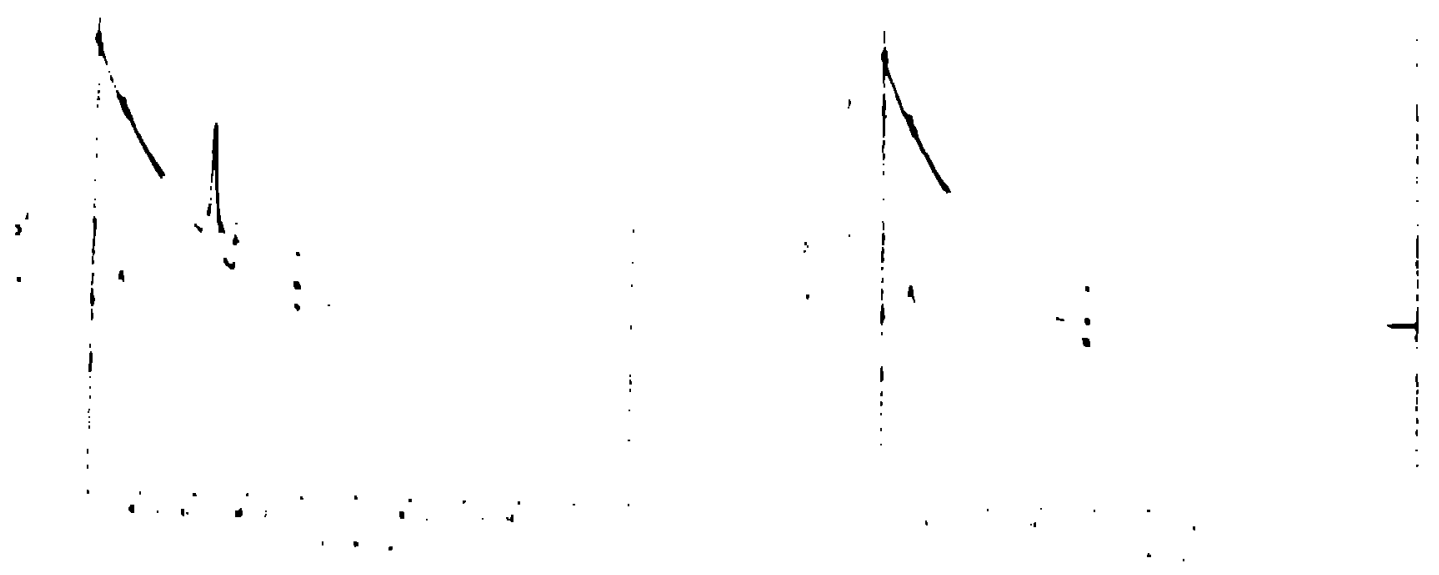

Figure 1. The monochromatic abeorption roefficients for a solar mixture for the ipproximate silar center conditions of $15 \times 10^{11} \mathrm{~K}$ and $150 \mathrm{~g} / \mathrm{cm}^{3}$. The iron bound-bound and bound-free transitions wre seen togecher with the free-free aboorptions from all the ions and the reparately shown free rlectron scaltering.

Figure 2. The monochromatic absorption coefficience for a solar mixlure without uon fir the upproxumate solar center conditiong of $: 5 \times 10^{\circ} \mathrm{K}$ and $150 \mathrm{~g} / \mathrm{cm}^{3}$. The iron line and hound-free pilge ure nuw alsent. and the oparity is reduced from $1.18 \mathrm{~cm}^{2} / \mathrm{g} 100.92 \mathrm{~cm}^{2} / \mathrm{g}$.
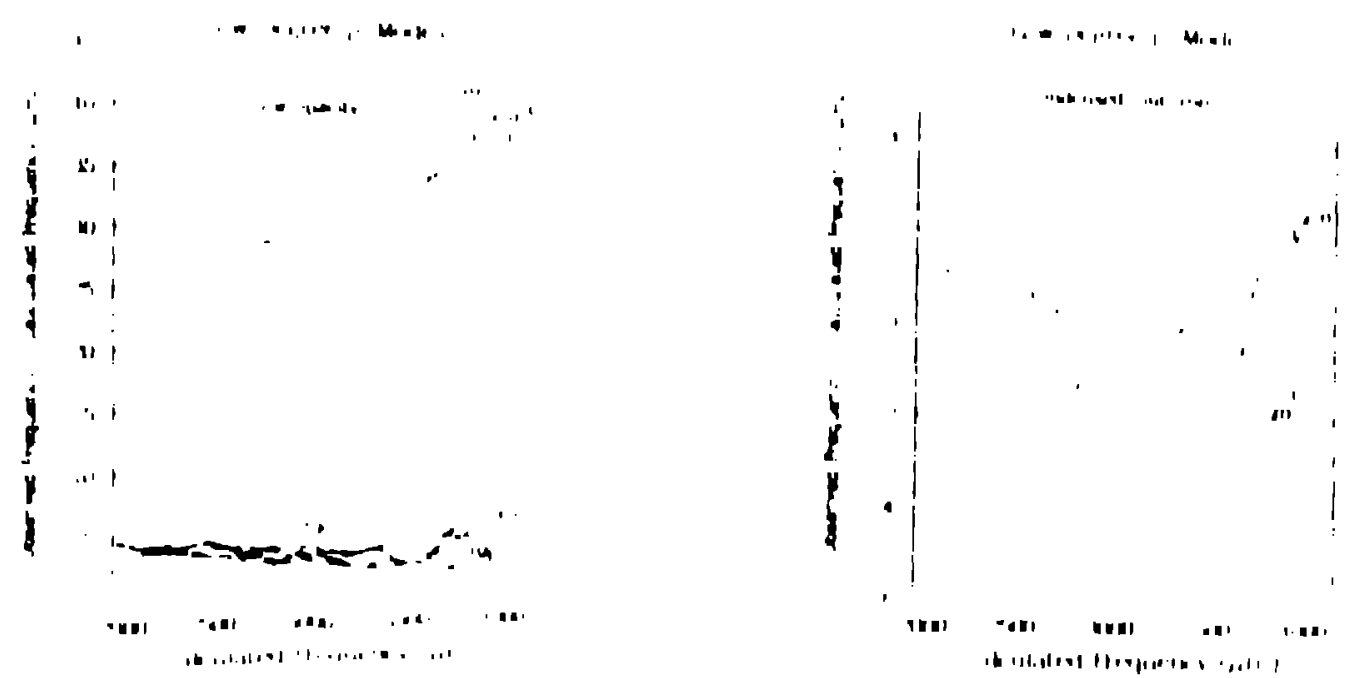

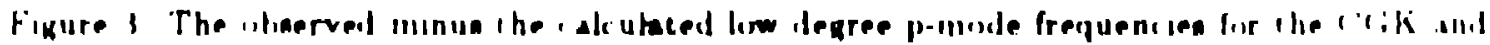

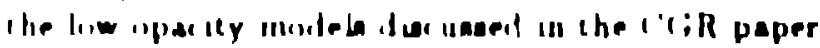

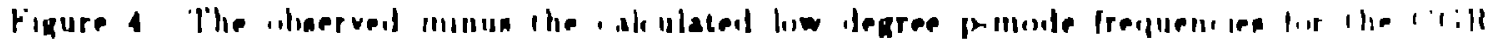

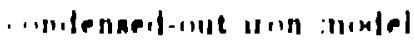


Figures 5 and 6 show the small difference, which we call $\delta(n)$ for the two models with and without iron. The $s(n)$, the lifference between the radial and quadrupole mode frequencies, has baen discussed by many others (see Cox. Guzik. and Raby, CGR 1989), and it is a seneitive indicator of the central model conditions. Agreement of predictione witb the observed frequency differences in the band of radial order 11 to 33, or, where the observations are more accurace, between 20 and 25 . indicates that a model represents the actual solar center. We see that both models are in reasunable skreement with observations. with the standard CGK one (normal iron abundance) slightly better

Collective effects have been frequently ciscussed as a way of reducing the electron scalterint photon attenuation at the solar center. The inost recent discusoion is by Boercker (1987) who refines the earlier work of Diesendorf and Ninhan (1989) and $r$ asendorf (1970). These latcer auchors have ssoumed that the angular dependence of the electron acatcering incegrated to zero, whereas for the non-vacuum solar conditions it does not. The result is a smaller opacity reduction. The correct reduction is about 25 percent, while the Los Alamos Astrophysical Opacity Library has a reduction at the solar center of about 20 percent, and the scattering in Ggures 1 and 2 above had no reduction at all. This matter seems to have been settled now, and its uncertainties are small, even though Bahcall and Irich (1988) calculate that the correct formulation gives opecities lower than the Opacity Library that is worth about a 9 percent reduction in the emergent calculated neutrino flux.

There is one additional appect of the collective effects. It coem that only the Los Alar so calculatione have included electron degeneracy effects for the Debye radius that enter in the collec(ive effects diecusion. The above mentioned 20 percent Los Alamon Astrophysical Opacity Libiary upacity reduction diecuesed by Boercker includes this electron degeneracy effect.

Recently there ha been thi idaa that there may be weakly interacing masive particles (WIMPs) that are numerous enough to supply the mising man of the universe, or at leat the insoing mase sround galaxies including ours. If these particlea of about 5 timea the proton mase really exise, then the Sun inevitably would collect many of them (one in $10^{11}$ protond) which would irbit in the inner 10 percent of the maes of the Sun. Even though they have an interaction crnes sertion of only about $10^{-10} \mathrm{~cm}^{2}$ with ordinary macter, they are an inportant source for conduction if energy from the solar center to several tımes ther orbit radius. Stuar Raby hu taken the work if othere surb a Spergel and Press (1985) in give a refined expreasion for the WIMP or Comion "pacizy This is

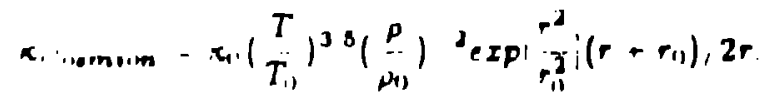

Fir the total opacity, ucluding the Cumion effects, the expreseion

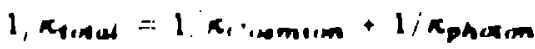

18 used. Fin the C'osmion opacity the values we have uned are $m_{n}=10^{-3}, T_{n}=13 \times 1 C^{n} \mathrm{~K}, p_{11}-2(00$ fim', und $r_{1},-0.0428$ colar radii.

sime wortere have amulated the conduction of the Comiono by conaidering them a an enetgy anure some dis. ance from the oolar center unatead of having them merely as anotier opacity

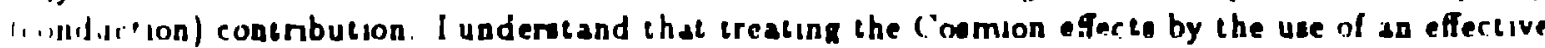
paity 4 more appropriase, and it does not lead to any inotability probleme that a few othere (De l.116 a el al, 1989) bave experienced.

With the an a given, corresponding t, the above Coumion abundance, the neutrino fux pror

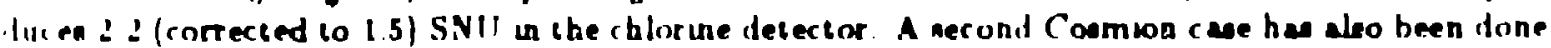
liy ("ik (19A9) with 9 imes lewer ('onnone giving ! 9 limes lager opecily, and that neutrino thux wives 4 (risterted in 3 5) SNI: Thu higher neutrino flux in juat on the border of being compalible

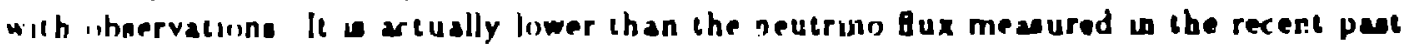

figure 7 dives apaun the ()-C' plot for the eame low degree outar p-modes for the two ('oumicin minteb The uparily aljuatment below the ionvertion oone, to be fieruased later, wall in the

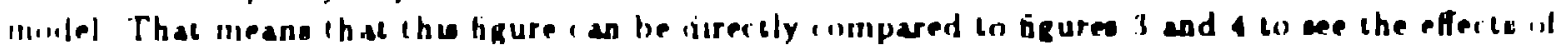



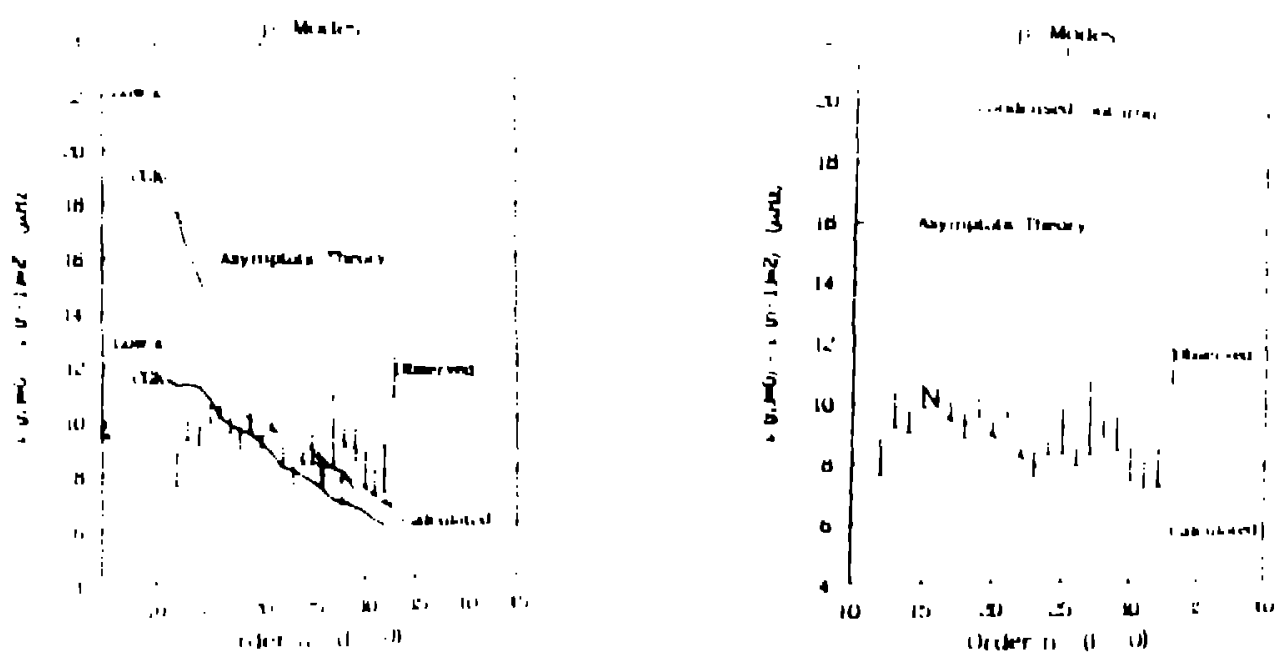

Figure 5. The $o(n)$ differences between the radial and quadrupule mode frequencies is plotted versus the radial order for the C'GK and the low opacity models. The obeervations are given with error bart as published by Jimener et al. (1988). Bcth the actually calculated eigenvalue frequency lifferences and the asymptotic theory variations are given.

Figure $b$. The $\delta(n)$ !)fferences between the radial and quadrupole mode frequencies is plotted vergus the radial order for the condensed-out iron model. The obeervation are given with error bars is published by Jimenes et al. (1988). Botb the actually calculated eigenvalue frequency differences and the aymptotic theory variations are given.
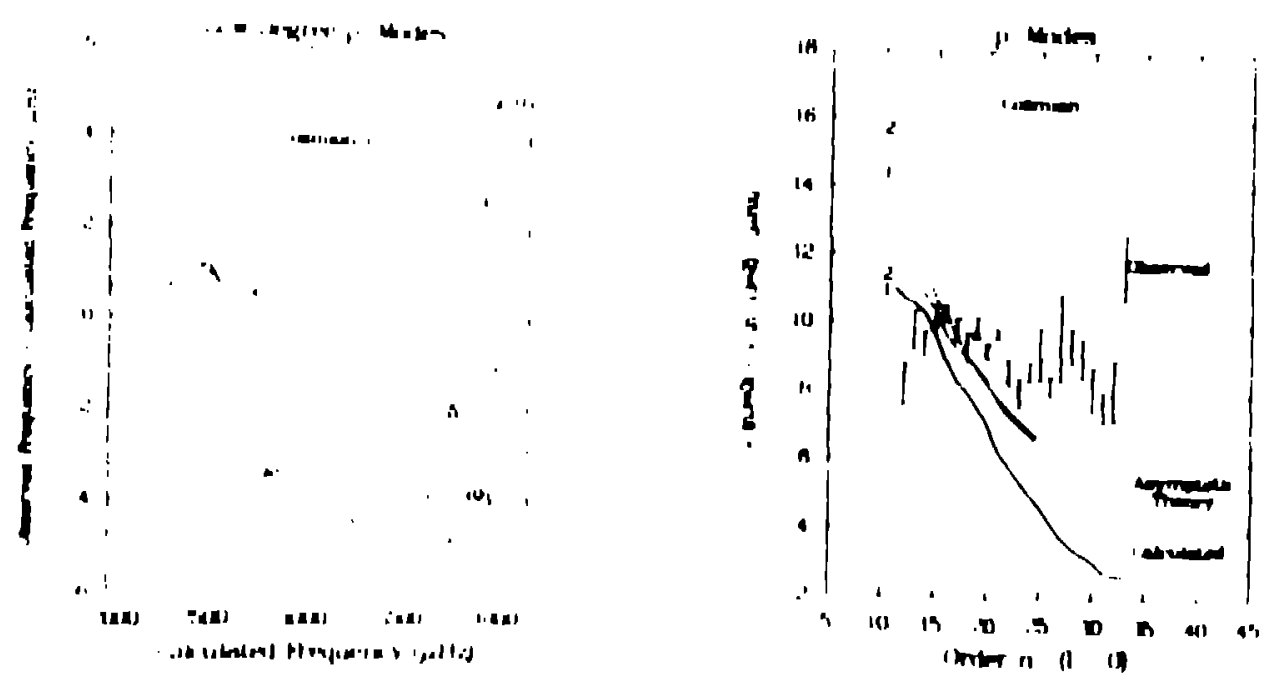

Figure 7 The riberved minus the caculated bon degree p-mode frequencies for the atantard Gininion model diec useed in the CGR paper

Figure $A$ The $A(n)$ iffiferences between the radial and qeadrupole mode frequencies w plotcel

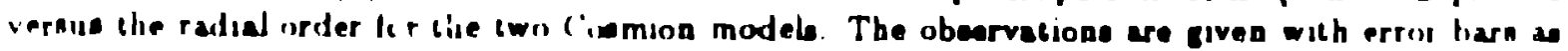
fililuhed by Junenes et a. (19A8) Bish the actually cakulated eigenvalue frequency iliferenies allil the aymptotic therory variatione are given. 
the Cosmions. The large spread of the differences between observation and prediction indicates that this model is not wo gond. Figure $B$ plots the $f(n)$ between the radial and quadrupole modes for this st andard Comion model and the one where the conduction bv the Cosmions has been reduced by a factor of 15.9. Theve plocs are in an Astrophysical Journal paper by CGR (1989). The reduced Cosmion number model with ito marginally acceptable larger neutrino flux still does not fit the observed p-mode frequency differences very well.

In a receot paper by Gilliland and Dappen (1988), it was suggeated that WIMPs actually solve the solar neutrino problem. This is because the cocillation $\delta(n)$ values seem to match thisse observed for models that had considerable number of WIMPs and a suitably low neutrino fux. This result conflicts with the data given here. The explanation probably is ibat, if the O-C curve is rather positive, as shown in an extreme for our low opacity case in Ggure 3 , then the $\delta(n)$ runs rather high as geen in figure 5. Gilliland and Däppen did not publish their O-C curve, but since they used the Eggleton. Faulkner, and Flannery (1973) equation of atate without the coulomb corrections, and they used the old low Cox-Stewart (1970ab) opacities, it it likely that the O-C curve is mostly positive. Then they would have a high $\delta(n)$ curve, which they also did not publish. These authors would need WIMPa to lower the $\delta(n)$, and its mean value they do diecus, by about the amount they have found by uning the older equation of atale and opacity data.

A final matter concerning the opacity at the solar center in one diecused by Bahcall and I Irich. During the wolar evolution most of the nuelear energy is from the proton-proton reactions, but there is some cycliug in the CNO proces. Thi later proces converte easeatially all the carbon to aitrogen, which is slow 10 interact in an proton capture reaction. Even some of the oxygen is changed to nitrogen. Bahcall and Lilrich auggeat that the opacity at the colar center in increaed by 7.8 percent due tc thi procensing. However, my recent detauled atudies show that this in incorrect reonlt. Uing a number of calculations, I find that the opacity is increased leas than one percent by this componition change.

Table 1 gives come of the comparisons kindly calculated by Joyce Gusit for the Rose-Aller (1976) mixture. This is different from the mixture given by Cax and Tabor 1576) and used for Ggures 1 and 2. She has ueed the Opacity Library to show that when all the carbon is asumed to be nitrogen (but the oxygen is unchanged in its abundance), the opacity in increaned by less than one percent. The track through the lable following the contral soler atructure is 1.16 kev at a density of 100 and $1.35 \mathrm{kev}$ at a density of 160 . Only the Library temperaluree have been used to avoid interpolation. Actually the CNO cycling effect gets inaller at bigher temperatures ana densities, merely redecting the growing contribation of the free ebctron acattering. Such an effect would be expected by inepecting Ggures 1 and 2 . All the bound-free edgee of the CNO elements are at very low photon energies, and the onby relic woen at the tilovolt photon energies and tilovolt temperature in the tresfree photon abeorption in the electric felds of the CNO ions.

The extensive work over the last 20 yean to reduce tbe deutrino outout has left us exactly where we were when we otarted. To colve the solar neutrino problem, I ouggeat that the neutrinos oncllate between their diferent types and interact with the electrons in the colar interiur as Bethe (1986) and Rowen and Gelb (1986) have euggested. This so-called MSW effect requires neutrinos to have mas and to ancillate between the three different types, but that is not so unreasuliable nowad ays.

\section{THE GOLAR SURFACE}

I'nid the lact few yoan, the opecity for the soler material at and juat below the photouphere was ubcaned from the Cax and Tabor (1970) iable. In lale 1979 Normao Magee kindly calculaled - opecial lon temperature table for the Roen-Aller (1976) composition uning the ame improver city program that was used to compule the Lo Alamos Aatrophyocal Opacity Library (Huebner 
et al.,197\%). These opacities included molecules, but they are quite unimportant for solar models. Russell hicman in 1983 then addeci Library opacities at the higher temperatures to form the RossAller 1 table that is now widely used by solar modelers. The interesting thing is that even though molecules are included, the main reason for a doubling of the opacity over the Cox-Tabor values is that iron lines are now calculated in much more detail than in the Cox-Tabor tables.

Figure 9 plots the logarithm of the ratio of the opacities from EXOP, as ased for the King IVa tible, to those from the Ross-Aller 1 table. Both tables have essentially the same composition.

Figure 10 gives the monochromatic absorption ccefficients versus photon energy for a temperature of 0.5 electron volt $(5800 \mathrm{~K})$ and a density of $3 \times 10^{-7} \mathrm{~g} / \mathrm{cm}^{3}$. The same plot using the Cox-Tabor data showiz only a few scattered lines instead of the forest of iron lines show $n$ in this figure and asso actually seen in the solar photosphere spectrum. It is interesting that over ten years ago, Huebner (1978) feit it important to display this very same plot to show the strong influence of the iron lines on the solar photosphere spectrum. Apparently the contour diagram given by Cox (1983) and repeated by Magee, Merts, and Huebner (1984), which shows the effects of lines for astrophysical opacity mixtures, missed a small island with a large opacity inciease at a temperature of $0.5 \mathrm{ev}$. Absorption lines are not important at temperatures lower than $4000 \mathrm{~K}$ because of the large effects of water vajor molecules, and above $8000 \mathrm{~K}(0.7 \mathrm{ev})$ hydrogen bound-fiee at sorption becomez dominant.

While for solar models we have aimost always used the Ross-Aller 1 opacities by calibrating the Stellingwerf (1975ab) 6t, others have used the Cox-Tabor opacity tables. Thus we do not directly know the relative effects of these two opacity tables on p-mode frequencies. According to Christensen-Dalsgaard, however, p-mode frequencies fit somewhat better when the newer Rose-Aller 1 opacities are used in the solar model.

I have considered the relative nonadiabatic effects of the King IVa (Cax-Tabor using EXOP) and the Ross-Aller 1 tables for the $p_{0}, l=60$ mode observed at $3036 \mu \mathrm{Hs}$. Figure 11 shows the work to drive pulsations per pulsation cycle versus sone number for the King IVa table in the mociel and in the oscillation eigensolution. These opacities were used (through the Stellingwerf fit) for the Kidman and Cox (1984) study of nonadiabatic effects on p-modes. The peak driving in at about p000K. The mode decays approximately as inferred from the obeerved p-mode line widthe in the spectrum. This can be seen from the figire because the integral over the driving (plotted per sone to make the integsal easier to see) is slightly negative.

When the Rose-Aller $i$ opacities are approximated by actually tripling the Stellingwerf opacity fit values, the puloation driving is given by figure 12 . Driving is now at a higher mass level where the temperature is again about $9000 \mathrm{~K}$, because the temperature gradient from the photosphere is steeper. In this case, however, the driving overwhelms the damping, and the mode is pulationally unstable. Thus the overstability of the solar p-modes depende sensitively on the opacity and monochromatic abeorption coefficients.

But care muat be taken. Radiation transport effects are not included in these calculations etther for the model atructure or for the oscillation eigensolutions. Also convection luminosity, which carries perhap $99 \%$ of the emergent luminosity at the mas level where the p-modes are driven, Is treated in our calculations a completely frosen-in. Therefore, a definitive otatement about the pulsation driving is not possible it seeme that modern nondiabatic calculations, for example the ratiation transport work by Christensen-Dalegaard and Frandsen (1983) or the radiation transpott and convection atudies by Balmford and Gough (1988), need to include the lateat Rome-Aller 1 iparilles in any case.

Modelers of stellar atructire have needed complete opacity tables for many mixtures, but at the moinent there are really only two motern ones. The Opacity Library allows opacity calculations inly down to 11, anOK temperalure, because molecular contributions to the absorption become important at temperaturea like A000K. Mixtures named Row-Aller 1 and Gromman! have been used to produce tables down to $2500 \mathrm{~K}$. This lack of tables ne now being rectified by Weine at Illinois and Munich who soon will have 20 additional tables, some with nignificantly different hydrogen and belium concerts 

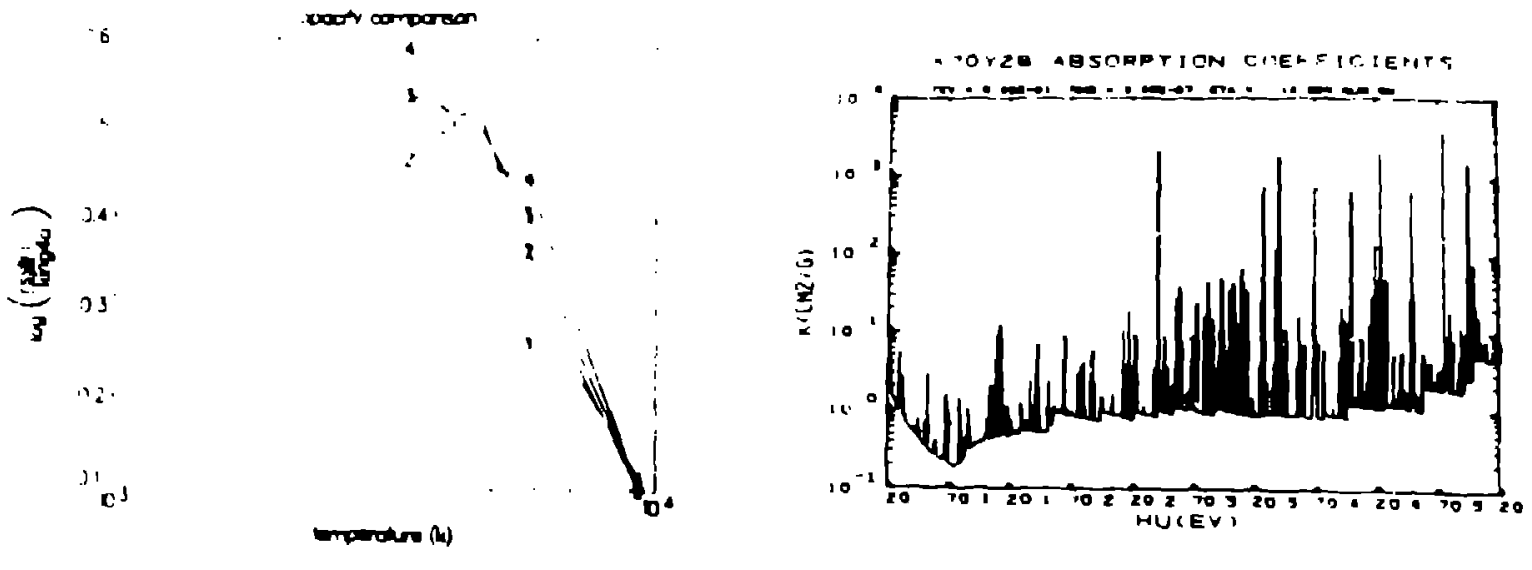

Figure 9. The logarithm of the ratio of the Rost-Aller 1 table opacities to the King IVa table opacities is plotced versus temperature for densities $3 \times 10^{-8}, 1 \times 10^{-7}, 3 \times 10^{-7}$, and $1 \times 10^{-0} \mathrm{~g} / \mathrm{cm}^{3}$. At the solar photosphere, the new Opacity Library opacities are twice that from the Cox and Tabor tables.

Figure 10. The monochromatic absorption coefficients for a solar mixture for the approximate so:us photosphere conditions of $5800 \mathrm{~K}$ and $3 \times 10^{-7} \mathrm{~g} / \mathrm{cm}^{3}$. On top of the dominant negative hydrogen ion absorption one can see the myriad of iron lines coming from transitions from the $M$ shell to higher levels.
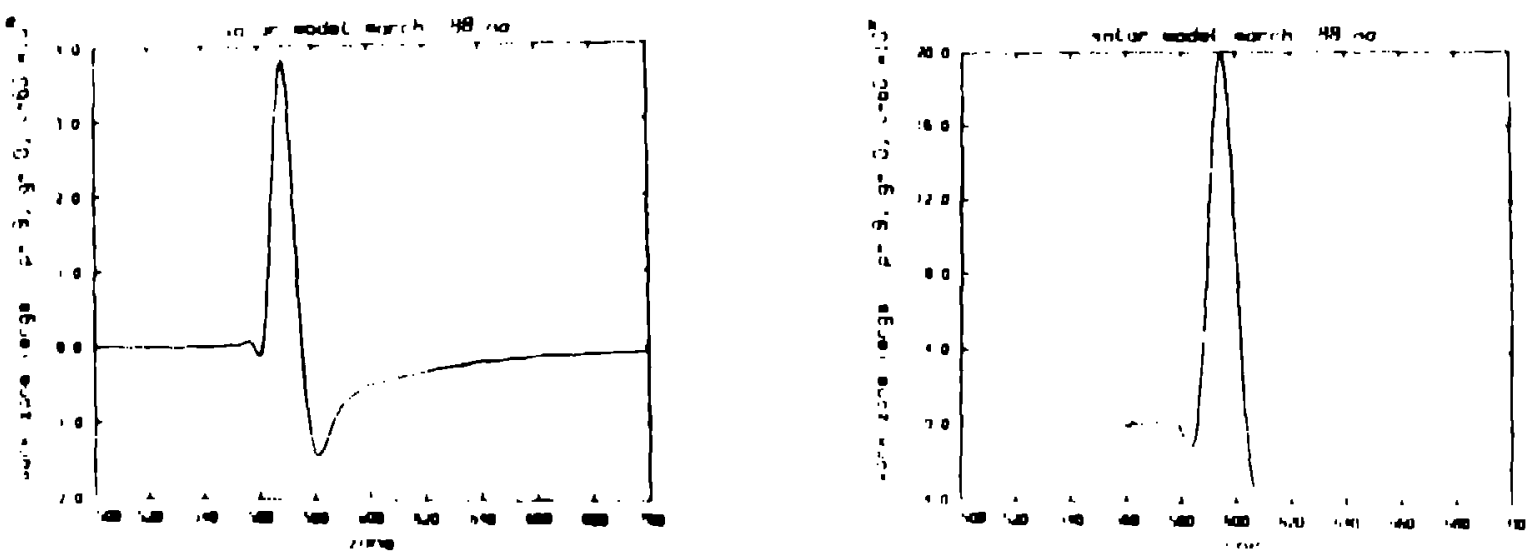

Figure 11. The work per cycle to drive oacillatione is plotted versus sone number for the outer 700 sones of the 1700 mass sose CGK model uning the Cax and Tabor King IVa opacity table. The peak driving at $9000 \mathrm{~K}$ is not large enougis to deatabilise the modt, and this po mode with $1=$ tio iecaye roughly al actually observed.

Figure 12. The work per cycle to drive oscillations is plotted vereus so se number for the outer 700 sones of the 1700 mas sone CGK modeI uning the Opacity Library Roen-Aller 1 opacity table tn calibrate the Stellingwerf ft. The peak driving at $9000 \mathrm{~K}$ is lerge enough to doutabilise the mode, and this $p_{0}$ mode with $l=60$ is predicted to be pulationally unatable. Otber atabilising effects surh w the radiation tranaport infuence on both the photonpheric atructure and the global oscillations se apparently more dominant. 


\section{BELOW THE SOLAR CONVECTION ZONE}

We have found that the solar p-modes are very sensitive to the opacity just below the convection zone. This sensitivity have been suggested by Christensen-Dalsgard et al. (1985) and more recently by Korzennit and Ulrict (1989). CGK (1989) adjusted the opacity upward by 15 to 20 percent in the 2 to 7 million kelvin region to get almost perfect agreement with all the low degree p-modes. Recent work by Christensen-Dalogaard, Lebreton, and Duppen (private communication) has shown that rod agreement with the observed p-modes can be fcund without adjuating the opacity from the Los Alamos Astrophysical Opacity Library at all. Thus oxly a small or even sero opacity adjustment may eventually be agreed upon.

Figure 13 shows the monochromatic absorption coefficients versus photon energy for a temperature of $3 \times 10^{6} \mathrm{~K}$ and a density of $0.4 \mathrm{~cm}^{2} / \mathrm{g}$, calculated by the EXOP opacity program. These conditions for the Cox-Tabor composition ubtain just below the solar convection sone. The strong bound-free edge at $0.76 \mathrm{kev}$ photon energy is from oxygen with 0.3 electron in the ls level. The other strong bound-free edge is from neon at 1.18 kev with 0.9 electron in ite $K$ shell. The only other significant $K$ edge is at $3.86 \mathrm{kev}$ from argon with both of ito lo electrons attached, but the $K$ edges of magnesium, aluminum, and silicon can just barely be seen. The carbon $K$ edge is off scale to the left, and the iron $K$ edge is of scale to the right. The edges at $1.4 \mathrm{kev}$ are the $\mathrm{L}$ edges of iron with 4.7 electrons in the $2 s$ and $2 p$ levels.

What can cause tae opacity uncertainty at these solar conditions? It does not seem that the CNONe ion hydrogen-like bound-free abeorptione can be in error very much. Or can the small free-free absorption be uncertain? The electron scattering, with the iron resonance lines neas 0.9 kev is small compared to other processes. It very well could be that the abecrption lines that are all from transitions with the lower level being $2 \mathrm{~s}$ or $2 p$ in $15,16,17,18$, and 19 timen ionised iron are much more numerous than we have indicated. The transitions to lovel $3 \mathbf{s ,} 3 \mathrm{p}$, and $3 \mathrm{~d}$ are near $0.9 \mathrm{kev}$, while the 2 to 4 and 2 to 5 transitinas are range from 1.0 to $1.4 \mathrm{kev}$, juat up to the $\mathrm{L}$ edges. Note that the level 6 in iron in destroyed by the continuum depreasion from neighboring charged particles. There in aleo the posoibility that with almont 0.7 electron in the 3 abell level that there can be some 3 to 3 iron line transitions, which we are not considering. It is not at all unreasonable that the opacity might need to be increased 20 percent for thi temperature and density. ! predict that the misaing opacity is due to the iron lines that are only partially dipplayed in figure 13.

We have calibrated the Iben (1975) opecity fit to calculate our enler modele and to solve fo: our accillation eigenolutions. For thin case, we have fond that a factor of 1.3 on a term called $A$, and a factor of 2.9 on the term $\kappa_{\text {, }}$ correct the Iben ft opacities to the Opacity Library valuet and then increase them by 15 to 20 percent in the temperarure range of 2 to 7 million kelvin. Figure 14 showe the lugarithm of the Roen-Aller 1 opecity to the Iben fit opecity ratio vernu temperature for the three dentities avilable in the Ron-Aller 1 table. 'The original tben fit is 20 to 40 percent too low in the bottom layers of the convection sone and deeper to a temperature of $1.0 \times 10^{7} \mathrm{~K}$. Figure 15 gives the 6t calibrated at atated above relative to the Rose-Aller 1 table. Now the calibration factorn mate the opacity larger by 20 percent at $3 \times 10^{\circ} \mathrm{K}$ and leat than 10 percent at $1.0 \times 10^{7} \mathrm{~K}$.

Figure 3 showe the $\mathrm{O}-\mathrm{C}$ plot for the two ben bi caese discuesed above. The original Iben fit gives very bow opacities in the region below the convection sone, and the fit to the low degree p-mode Gequancies is very poor. The dramatic improvement, providing that the equation of atate is otherwine accurate, can be uned to varify the eccuracy of the solar opacities.

The $\delta(n)$ that correaponds to the low opacity cane of figure 3 is given in figure 5 . The 'arger ggure 3 O-C values give larger $\delta(n)$ values. The sensitivity to the opacity decreases above $1-10$, because the higher degree modes have turning points nearer to the cunvection sol bottom ir even in it. Then the amplitude in the deeper evanescent regions in not large enough to a ect sig'ificantly the oscillation periods. 

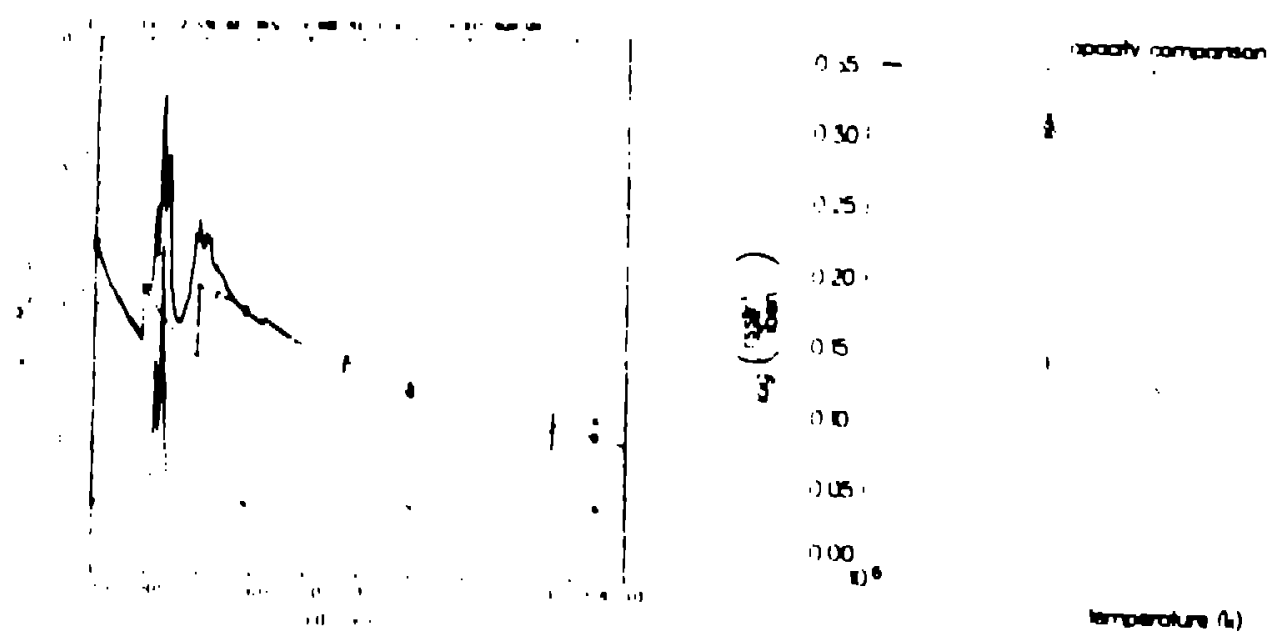

1

Figure 13. The monochromatic absorption coefficients for a oolar mixture for the apprixim.ste solar conditions below the conveceion sone of $3 \times 10^{6} \mathrm{~K}$ and $0.4 \mathrm{~g} / \mathrm{cm}^{\mathrm{J}}$. Aboorption $\mathrm{K}$ edges uf , xygen. neon, magnesium, aluminum, silicon, and argon can be seen. Also at 1.4 kilovolt photon witruy weak closely spaced $L$ edger of iron are visible.

Figure 14. The logarithm of the ratio of the Rose-Aller I table opacities to the lhen fit frum murw upacities is plotted versue temperature for denoitiee $1 \times 10^{-1}, 1 \times 10^{0}$, and $1 \times 10^{1} \mathrm{~g}$. conditions, the new Opacity Library opacities are cunsiderably larger than those from the llien fit uriginally calibrated to the Cox-Stewart opacities.

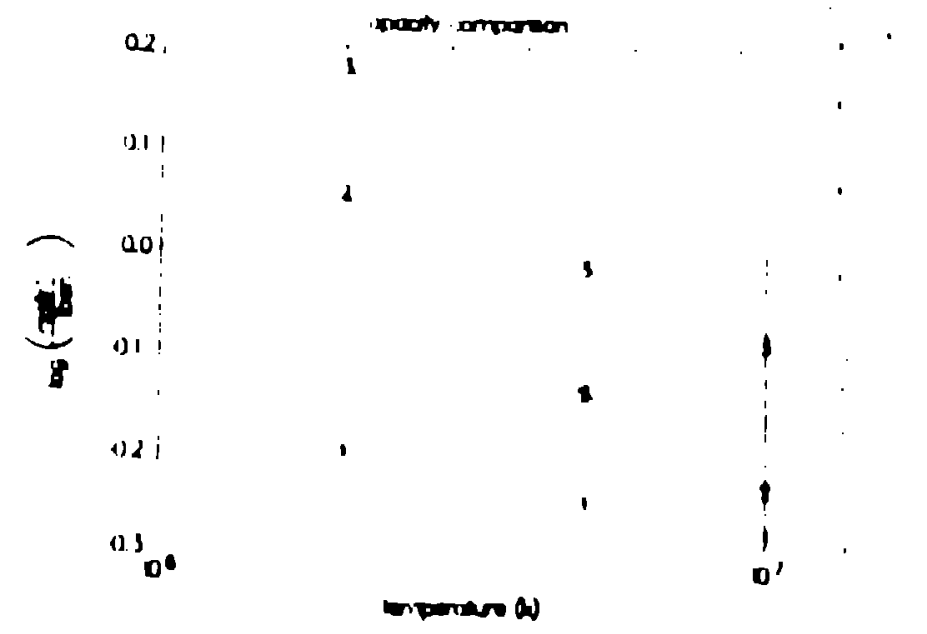

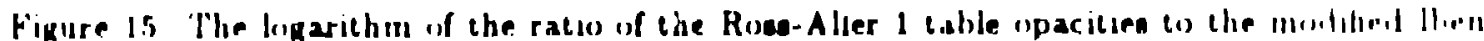

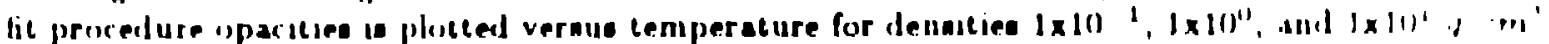

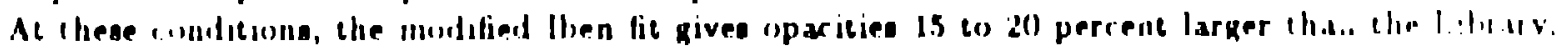

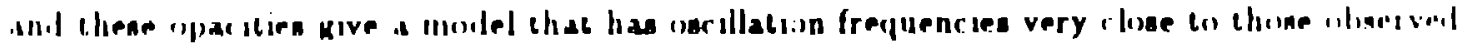

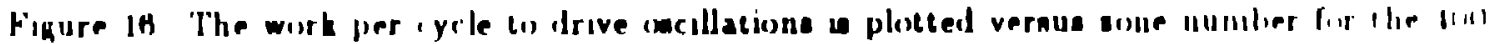

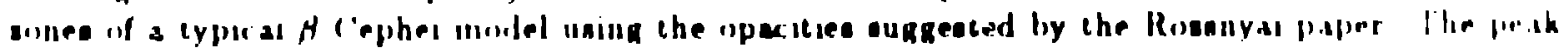

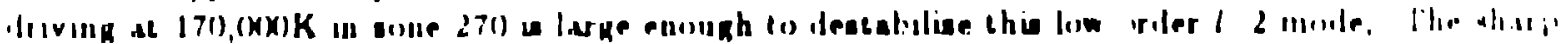

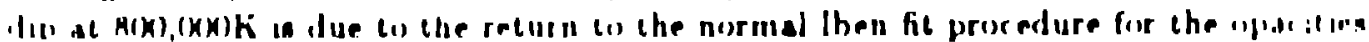




\section{OPACITY EXPERIMENTA}

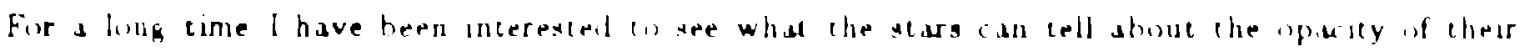

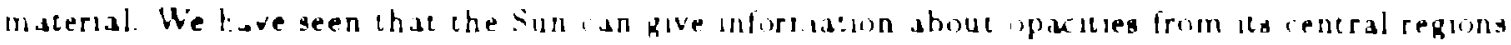
its surface structure, and its atructure at and below the convection sone At the center, we concluble that opacities are reasonahly acurate, becauge we an wcurately predict the actual uhserved hiw

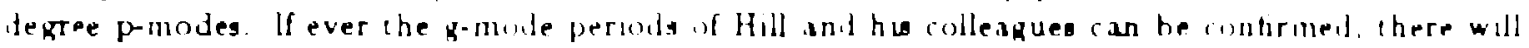
be an even stronger verification of the solas ienter upacities. These published g-mode periods are very near that expiced for the standard solur model without any internal mixing luring its líe li does seem that condurtion by $c$ osmous is noc supported by current g-mode perist arvacions bulicy

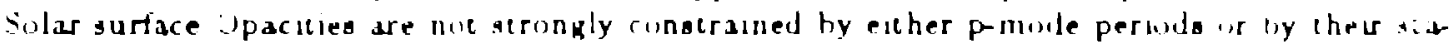

In the region below the convectorn zone, we have a rachei inceresung opscicy experiment riti have suggested a needed increase, hat ( hristensen-Dalagard and collaboratora find that an increise ts not so necessary. The issue of the importance of uron lines, yeen at the anvection sone botturi. arises again in the context of the $f($ st $a r s$ in the Hyades cluster and for clanical variable stare.

There is a problem with the predictions for the lithium abundance in the Hyades cluater (; tuss. Sirungfeilow. Swenson, and Faulkner (i9g7) have broughe actention (1) tha problem that may be important for stellar upac ics le ippears that the convection anne lepth un rurrent scellar models needs to be incroased rather hk: ihat to predict correcily the olas p-mode frequencies and even the solar lithim depletion. A mulest ipacity increase would very much help thu ilociepancy with observations that show hithum ifplecion (presumably by nuclear processing) occurs for hotter (i type staro than the experts predict with clasoical opacity values. ('an the uron lines increwe the upacily and solve the problem:

Audreasen and Petersen(1988) and Anilreasen (1988) have pointed i, ut that a large upa ity increase suggesteci hy Simon (19R2) to anlve a perod ratio problem for the clasoical toublemole

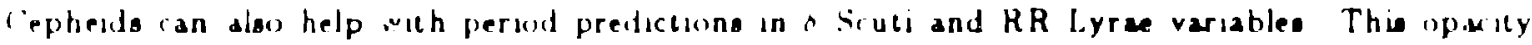
increase has been diacuafed by Magee, Merta and Huebner (1984), and such a large increase over auth a large cemperalure range wa not found libely lalesias. Kogers, and Wibon (1987) however. have

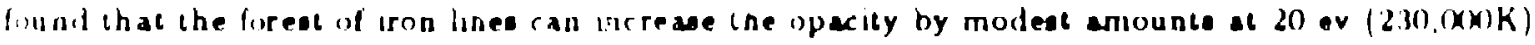
iemperacure Theu lacest unpublighed reaules rite a fartor if 22 opacily increae at a denally il

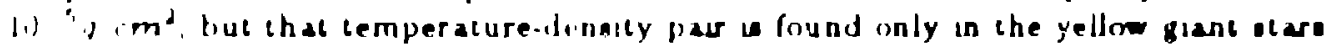

Mure recently Rosanya (1!389) han proproed even more ron lines, and he finda very !are npailty

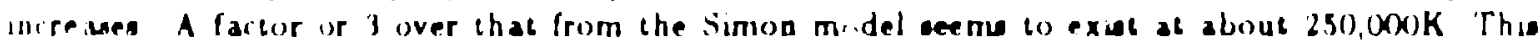

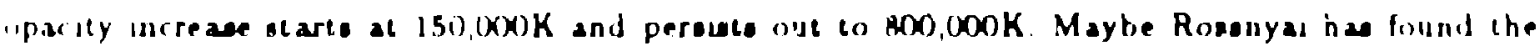

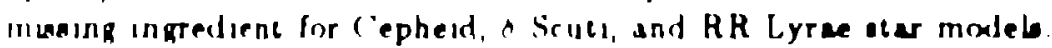

For yeas, there ha been the problem of how the $f$ rephes variables pubate lavertikatione if many premitle mechaniema ha alwaya ahown, with careful otuds, that chey cannot make these nian inatable, at leat in the linear nonadiatiatic theory. I now thint that increaed upacietes may give

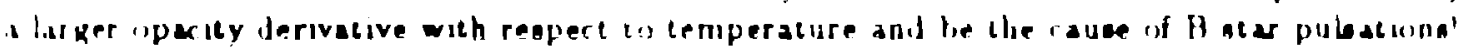

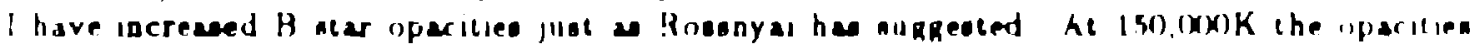
we the from the Opacily library tumes a factor that linearly increape co three al a cemperatire

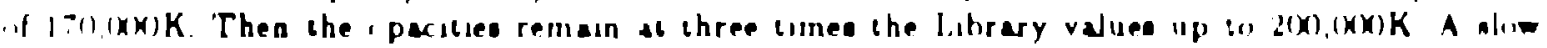

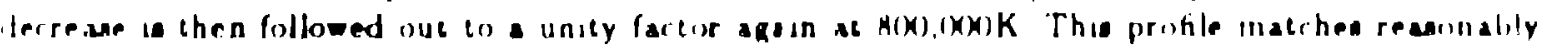

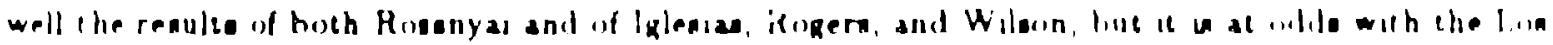

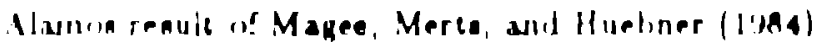

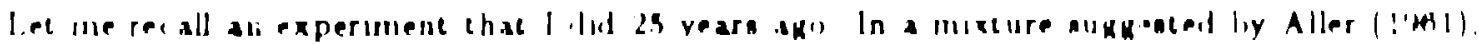

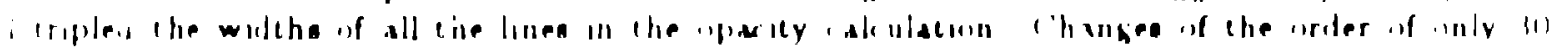

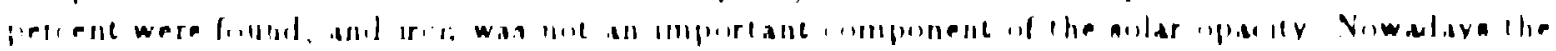


iron abundance b ten times lagger in the solds muxture, and an ispacity increase by tripling the litie widihe w much larger The Rusanyai inirease wo not unreasonable

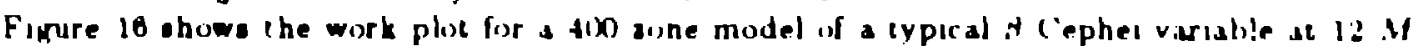
With the rapid opacily increase with temperalure, idued by the sasumed suliten inset if the

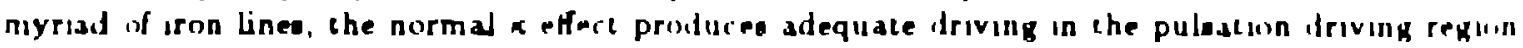

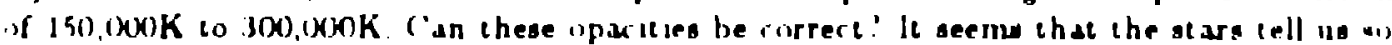

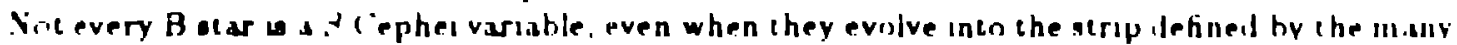

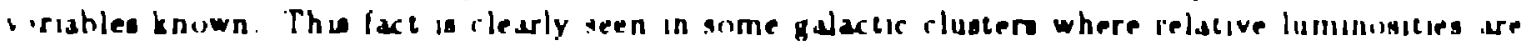
now an unknown factor I guggeat that the iveratability is undeed a funcuon if the iron abunitinie With a nurma solar uon abunidance, there may nut be enough driving, hut of there wanly a tikht trun enhancement (but nist due to kravitational cettling or radiation levieation that we ialculate $1 .$. he a amall effect, however), then the iron lines is have an oigniticanteffect in the atellis ip.u ity Mi.l stellar stability

\section{O. REFERENCES}

Aller. 1. H I'w I The dbundance of the Elements, (New York: Interscience Publuhers)

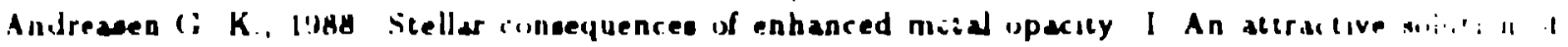
che c'ephesd perioil racio descrepancies Astron. Astrophys, 201, 72

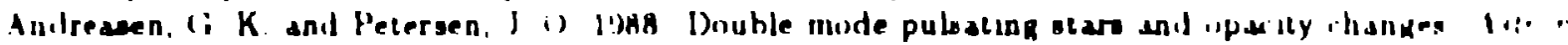
Alrophys, 102, Lt

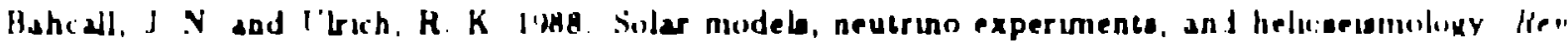
lfod thys, 60, 297

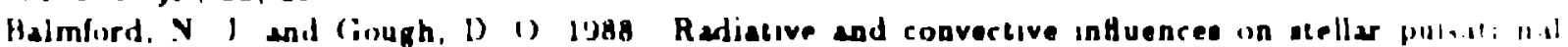
itahilaly ieumolowy of the iun und jun Late jiars, ESA SP 2a6, ed. E J Rolfe. p 4 ?

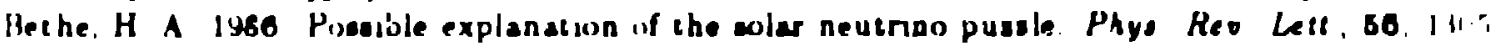

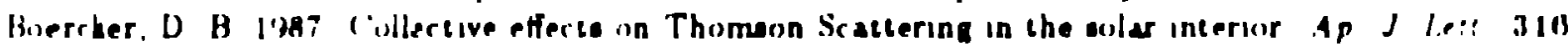
1., $1 \mathrm{~A}$

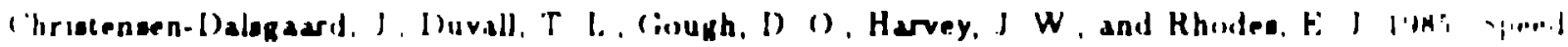
if anund in the whar inceriur . Visture. 318, 378.

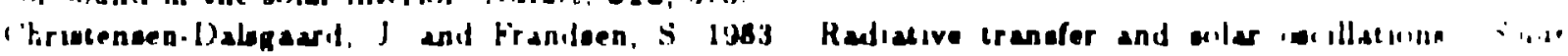
['iyskes, 02, 165

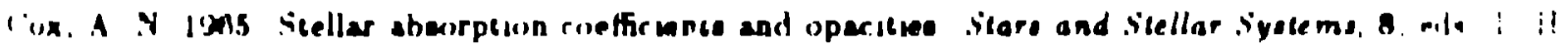

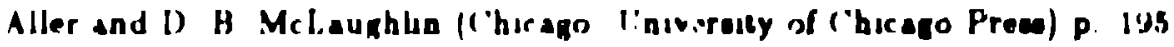

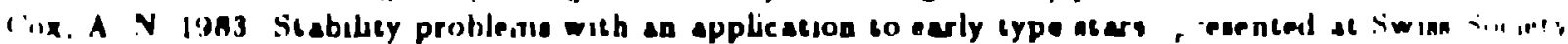

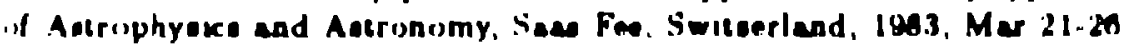

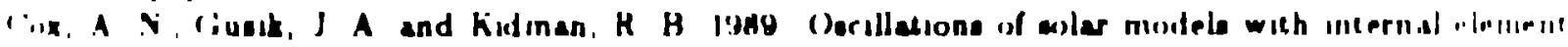
liffueng Ap J. S42, 1187

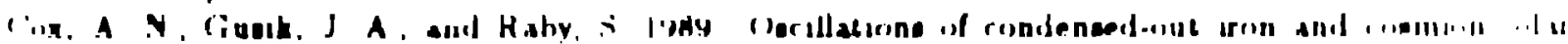
mistolo. Ap J, oubmiliad

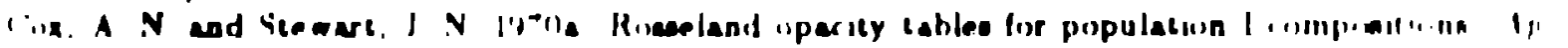
$\therefore$ iupl, 10, 243

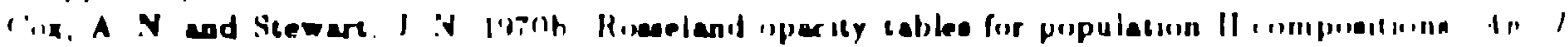
iuppl, 10, 2nI

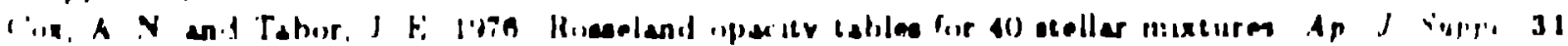
$i i 1$

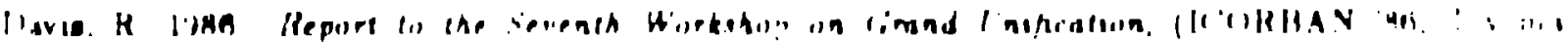
lpanl. | :17 


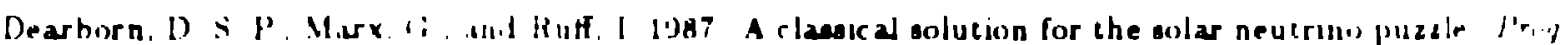
Theo Phyg. 77. 1:

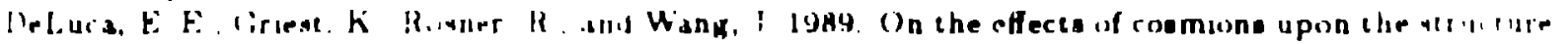

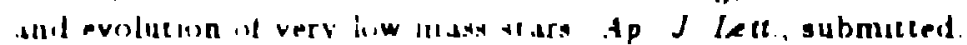

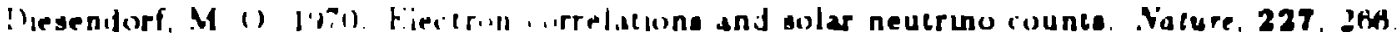

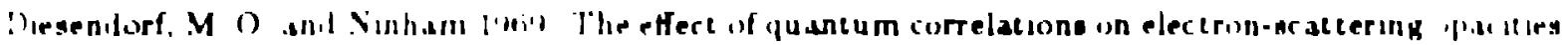
If J, 156. I(t)ill

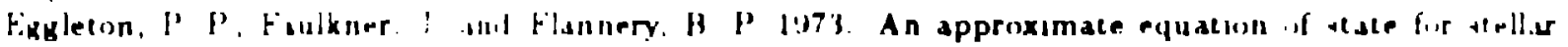
material tecron tieriphus as ber

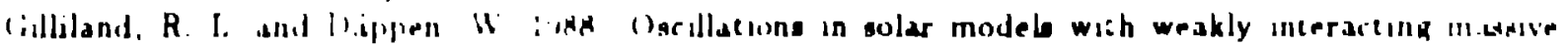
parci:les. Ap I. $324,11 r_{1}$

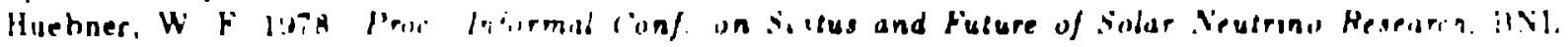

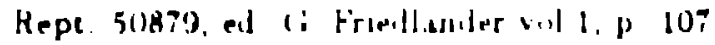

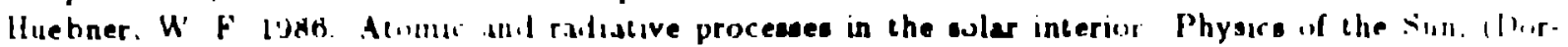
lieche [) Reldel Publewhin ('impinyl, 1, p 13

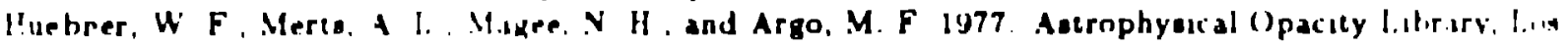

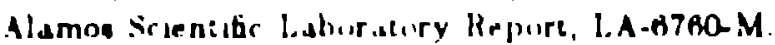

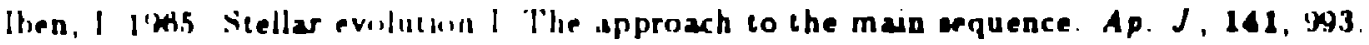

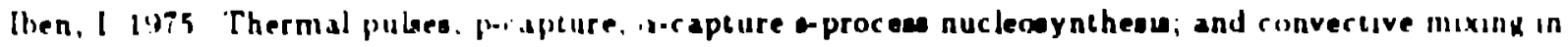
a hiar of uncermediale mun ip J, $100,549$.

Ixleoia, ( A, Rugers, F I, Mul Wilson, B. G. 1987 Reexamination of the metal contributiun in werophynical uparity ip $J$ l,ell $.322,1,45$.

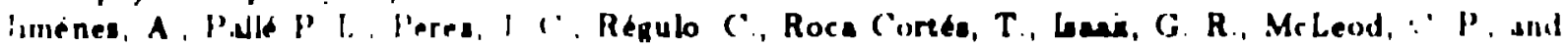

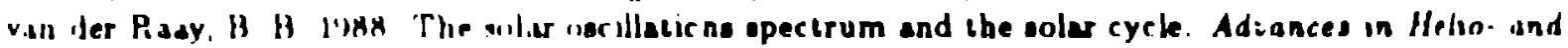

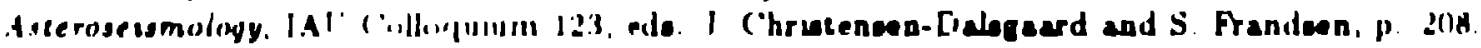

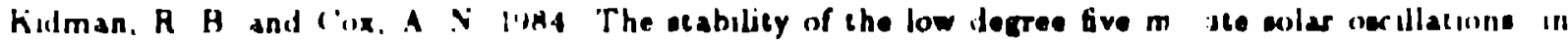

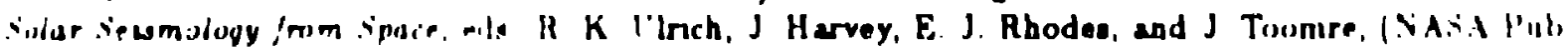
$4+4)$, p 115

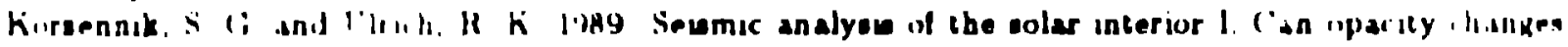
improve the theoretical treiguencien' Ap J,330. 1144

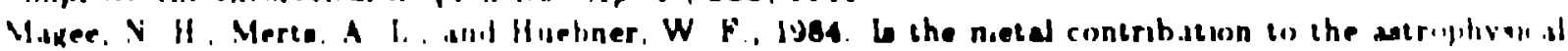

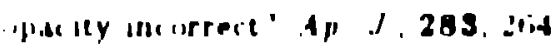

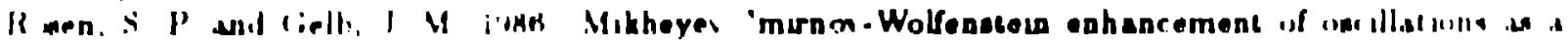

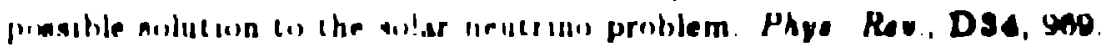

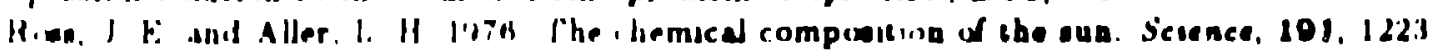

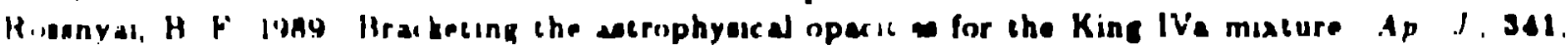
114

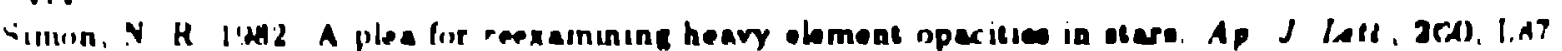

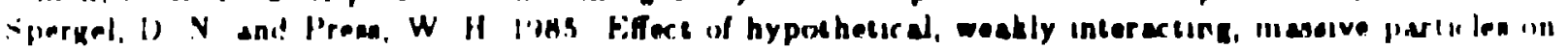

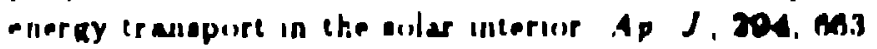

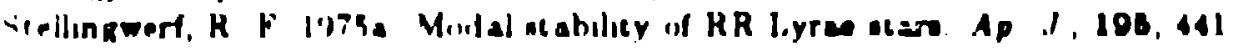

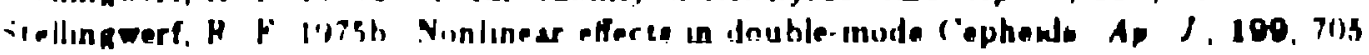

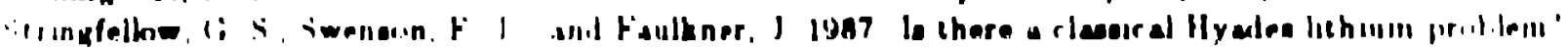
114.510. 11:11

\begin{tabular}{|c|c|c|c|c|c|c|}
\hline 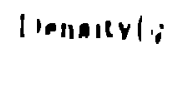 & 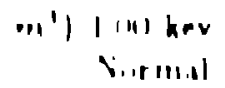 & $\begin{array}{l}\text { I III) kav } \\
\text { V., I. }\end{array}$ & $\begin{array}{l}\text { I Li kev } \\
\text { Nirmal }\end{array}$ & $\begin{array}{l}125 \text { kev } \\
N_{11} 1 .\end{array}$ & $\begin{array}{l}1 \text { sol ked } \\
\text { Normal }\end{array}$ & $\begin{array}{l}\text { S1) hey } \\
\text { Nole }\end{array}$ \\
\hline $\mid(x)$ & $1+11$ & 1 (sts) & I I:A & I IAด & 1) AB: & 1) MAM \\
\hline $1: 11$ & $\therefore 1: 2$ & $\therefore 11+i$ & $12(11)$ & 1271 & 3'11 & (1) \\
\hline $1 ', 1$ & $\therefore \quad \therefore 4$ & $\therefore: 14$ & $11: 85$ & 1417 & (1) 'נABn & $(1)$ \\
\hline$|(1)|$ & $\therefore 1 a^{\prime}+i$ & $\therefore$ IIA & 1415 & 1447 & $I(x) A$ & 11112 \\
\hline
\end{tabular}

